\title{
MATERNIDADE NA ETNOBIOLOGIA: DESAFIOS ENCONTRADOS POR PESQUISADORAS QUE SÃO OU BUSCAM SER MÃES
}

\section{MOTHERHOOD IN ETHNOBIOLOGY: CHALLENGES ENCOUNTERED BY RESEARCHERS WHO ARE OR WANT TO BE MOTHERS}

\author{
Flávia Rosa SANTORO ${ }^{1}$, Barbara Arias TOLEDO ${ }^{2}$, Juliana Loureiro de Almeida CAMPOS ${ }^{1}$, Andrêsa Suana \\ Argemiro ALVES ${ }^{1}$, Letícia Zenóbia de Oliveira $\mathrm{CAMPOS}^{3}$ \\ ${ }^{1}$ Laboratório de Ecologia e Evolução de Sistemas Socioecológicos, Centro de Biociências, Departamento de Botânica, Universidade \\ Federal de Pernambuco, Cidade Universitária, Recife, Pernambuco, Brasil. ${ }^{2}$ Facultad de Ciencias Exactas, Fisicas y Naturales, \\ Universidad Nacional de Córdoba, Avenida Vélez Sársfield 299 - Córdoba, Argentina. ${ }^{3}$ Centro das Ciências Biológicas e da Saúde, \\ Universidade Federal do Oeste da Bahia, Barreiras, Bahia, Brasil \\ * flaviarsantoro@gmail.com
}

Submitted: 09/11/2020; Accepted: 23/12/2020; Published: 27/02/2021

\section{RESUMO}

Entre as inúmeras desvantagens que as mulheres encontram na carreira científica em relação aos homens, a maternidade tem sido apontada como um fator limitante para o acesso e permanência das mulheres na ciência. No campo específico da Etnobiologia, há evidências de que as mulheres brasileiras sofrem preconceito no meio acadêmico por serem mães, deixando de serem selecionadas para ocupar determinadas vagas em universidades pelo fato de terem filhos pequenos. Em outras áreas da ciência, estudos mostram que mesmo a intenção em ser mãe pode influenciar negativamente nas oportunidades oferecidas às mulheres no meio acadêmico. Além do preconceito e menores oportunidades, diversos desafios são superados constantemente por mães etnobiólogas, desde as dificuldades para realizar trabalho de campo com crianças pequenas até a necessidade de conciliar uma razoável produção acadêmica e a criação dos filhos. Através da percepção de etnobiólogas da Argentina e do Brasil, acessadas por meio de questionários on-line, esse trabalho teve como objetivo mostrar o cenário vivido por etnobiólogas que são mães e/ou que desejam ser mães, em busca de iniciar uma discussão sobre possíveis estratégias capazes de diminuir as dificuldades encontradas entre a vida acadêmica e a maternidade no campo da Etnobiologia. Encontramos que a maioria das etnobiólogas percebe um ônus ao conciliar sua carreira com a maternidade, principalmente refletido na dificuldade em poder realizar seu trabalho de campo como planejado e na diminuição da quantidade e qualidade de sua produção científica.

PALABRAS CLAVE: Etnociências, Filhos, Maternidade na ciência, Gênero, Vida acadêmica.

\begin{abstract}
Among the disadvantages that women encounter in their scientific careers in relation to men, motherhood has been pointed out as a limiting factor for the access and permanence of women in science. In the specific field of ethnobiology, there is evidence that Brazilian women suffer prejudice in the academic environment because they are mothers, ceasing to be selected to occupy certain places in universities due to the fact that they have small children. In other areas of science, studies show that even the intention to be a mother can negatively influence the opportunities offered to women in academia. In addition to prejudice and fewer opportunities, several challenges are constantly overcome by ethnobiologist mothers, from the difficulties in carrying out fieldwork
\end{abstract}


with young children to the need to reconcile reasonable academic production and the upbringing of children. Through the perception of women ethnobiologists from Argentina and Brazil, accessed through online questionnaires, this work aimed to show the scenario experienced by ethnobiologists who are mothers and / or who wish to be mothers. This work intends to start a discussion about possible strategies capable of reducing the difficulties encountered by ethnobiologists when they decide to reconcile motherhood with academic life. We found that most ethnobiologists perceive a onus when reconciling their career with motherhood, mainly reflected in the difficulty in being able to carry out their field work as planned and in the decrease in the quantity and quality of their scientific production.

KEYWORDS: Ethnosciences, Children, Motherhood in science, Gender, Academic life.

\section{INTRODUÇÃO}

Ao longo da história, homens sempre estiveram à frente de cargos de liderança em empresas, universidades e institutos de pesquisa. Entretanto, após a década de 1970, percebeu-se o aumento no número de mulheres no mercado de trabalho (FIORIN et al., 2014). Essa conquista se deu, inicialmente, por mulheres jovens, solteiras e sem filhos, e somente mais tarde é que o número de mulheres casadas e mães que realizam atividades remuneradas fora do lar teve crescimento (BRUSCHINI, 2007). Apesar desse notório crescimento, permanecem as responsabilidades das mulheres pelas atividades domésticas e cuidados com os filhos e outros familiares, evidenciando a permanência de modelos familiares tradicionais que sobrecarregam as trabalhadoras, principalmente as que são mães de filhos pequenos (BRUSCHINI, 2006).

No campo das ciências, ainda que algumas equipes de investigação tenham incorporado uma concepção feminista de gênero às suas práticas e conhecimentos ao longo das últimas quatro décadas (ORTIZ GÓMEZ, 1997), a desigualdade de gênero ainda é perceptível. Esta desigualdade se mostra clara quando se observa que, apesar de as mulheres serem maioria entre ingressantes e graduadas/os em carreiras científicas, são minoria nos cargos mais valorizados, experimentando um fenômeno conhecido como "teto de cristal" (GUILL BOZAL, 2008). Willians e Ceci (2012) se debruçam sobre algumas possíveis causas de tal disparidade: uma suposta diferença de habilidades científicas intrínseca entre homens e mulheres; distintas preferências de carreira e estilo de vida; discriminação de gênero por revisores nas publicações e agências de financiamento; e a escolha por ter filhos. Após destrincharem o peso de todos esses pontos, os autores chegam à conclusão de que um único fator explica grande parte da escassez de mulheres na ciência: a maternidade. Segundo esses autores, até mesmo a intenção de ter filhos pode ser 
responsável pela desistência das mulheres na carreira científica, ou um atraso em atingir os mesmos cargos acadêmicos que os homens.

Cech e Blair-Loy (2019) também mostram que a disparidade entre gênero ainda é grande em muitas áreas científicas e que esse desequilíbrio ocorre principalmente após o nascimento de filhos: novas mães têm mais probabilidade do que novos pais de deixar a carreira científica, mudar para um trabalho de meio período ou ficar desempregada. Notoriamente a parentalidade não afeta os pais na mesma proporção que as mães.

Dentro da área da Etnobiologia, na qual as investigações estão pautadas nas relações entre as pessoas e os recursos naturais, a questão de gênero também é notada. Recentemente, os desafios e perspectivas de etnobiólogas no Brasil foram discutidos em um trabalho em que as autoras mostram que existem diversas situações de sexismo no campo da Etnobiologia, e destacam, entre tais situações, o preconceito que etnobiólogas sofrem na academia pelo fato de serem mães (SILVA et al. 2019).

No Brasil, quando se trata de discussão sobre maternidade e paternidade no mundo acadêmico, o grupo Parent in Science é referência (https://www.parentinscience.com/). Uma pesquisa realizada pelo grupo mostra que $81 \%$ das cientistas brasileiras consideram que a maternidade teve impacto negativo em sua carreira científica, enquanto que apenas $7 \%$ consideram esse impacto positivo e 12\% consideram neutro (MACHADO et al. 2019). A mesma pesquisa aponta que a produção acadêmica das mulheres cai significativamente após o nascimento de um filho, voltando a crescer somente cerca de quatro anos depois (MACHADO et al. 2019).

Apesar dessa importantíssima discussão, existem poucos grupos no mundo realizando pesquisas com o intuito de entender o impacto da maternidade na ciência. $\mathrm{Na}$ América Latina, só encontramos trabalhos com dados do Brasil, embora esse tema venha sendo timidamente discutido em alguns laboratórios de pesquisa. Nosso trabalho pretende aprofundar essa discussão no campo da etnobiologia, levando em consideração alguns aspectos específicos dessa área da ciência a partir de perspectivas de etnobiólogas do Brasil e Argentina. Buscamos, então, levantar alguns desafios, questionamentos e perspectivas de etnobiólogas que são mães ou pretendem ser-lo, a fim de discutir o que pode ser feito para que a conciliação da maternidade com o trabalho acadêmico em etnobiologia ocorra sem grandes prejuízos para o avanço da ciência, estabilidade profissional e para a qualidade de vida pessoal dessas mulheres.

\section{MATERIAL E MÉTODOS}


SANTORO et al. Maternidade na Etnobiologia: desafios encontrados por pesquisadoras que são ou buscam ser mães.

Ethnoscientia v.6 n.2, especial, 2021. DOI: 10.22276/ethnoscientia.v6i2.372

\subsection{Seleção das participantes da pesquisa}

As participantes da pesquisa foram selecionadas por meio da técnica da bola de neve (ALBUQUERQUE et al. 2014). Esta técnica consistiu em selecionar um primeiro grupo de participantes e solicitar às mulheres que responderam ao questionário que indicassem outras mulheres que, assim como elas, pudessem se encaixar no perfil referente ao assunto requerido, a fim de que o procedimento fosse repetido até que não houvesse indicações de novas pessoas. Assim, iniciamos a bola de neve a partir do encaminhamento de e-mails, os quais continham além da apresentação do trabalho, os links de acesso aos formulários (anexo 1), para pesquisadoras reconhecidas por trabalhar com etnobiologia no Brasil e Argentina, solicitando que as mesmas os encaminhassem a outras pesquisadoras da área. Buscamos fazer uma primeira seleção de etnobiólogas de diferentes regiões destes dois países, abrangendo distintas características geográficas, culturais e socioeconômicas. Inicialmente foram enviados 48 e-mails para etnobiólogas do Brasil e 120, em três envios consecutivos, para biólogas da Argentina.

No e-mail de chamada para pesquisa, evidenciamos que estávamos buscando mulheres que se auto reconhecem como etnobiólogas e que sejam ou desejam ser mães (anexo 1). Ficou a cargo de cada participante decidir seu enquadramento no perfil explicitado. Foram incluídas mulheres com graduação já concluída, que estivessem realizando ou concluído mestrado, doutorado e/ou pós-doutorado, além daquelas que tenham cargo de pesquisadora e/ou professora universitária, ou tenham tido qualquer vínculo com universidades ou instituições de pesquisa recentemente e que reconheçam sua área de atuação no campo da etnobiologia, principalmente. $\mathrm{Na}$ amostragem foram incluídas mulheres de diferentes raças, etnias e classes sociais, independentemente da orientação sexual da participante.

\subsection{Coleta de dados}

Para coletar informações a respeito da percepção e perspectivas de etnobiólogas sobre a conciliação da maternidade com a carreira científica, foram elaborados três questionários distintos (ALBUQUERQUE et al. 2014). Utilizamos como modelo os questionários realizados pelo grupo Parent in Science, porém realizamos diversas modificações para atender nossos objetivos de pesquisa. Os três diferentes questionários foram voltados para: 1) mulheres que foram mães enquanto já seguiam sua trajetória acadêmica, 2) mulheres que foram mães antes de iniciar sua trajetória acadêmica e; 3) mulheres que ainda não são mães mas pretendem ser; no intuito de acessar perspectivas 
diversas sobre a maternidade na vida acadêmica de etnobiólogas (anexo 2). Os questionários foram empregados através da plataforma online gratuita google forms e cada participante foi informada que deveria escolher qual questionário responder de acordo com sua situação em relação à maternidade (ver chamada à pesquisa, anexo 1). Mulheres que não são ou não pretendem ser mães não foram consultadas. Salienta-se que o completo anonimato foi garantido para todas as participantes da pesquisa.

Os questionários incluíram perguntas como data de nascimento da entrevistada, etapa do percurso acadêmico em que estavam, número de filhos e data de nascimento de cada filho. Além disso, todos os questionários incluíram questões sobre o impacto que a maternidade pode causar na qualidade e quantidade da produção científica, de acordo com a percepção de cada participante. As participantes tinham a opção de responder se com o advento da maternidade havia aumento, diminuição ou estabilidade quantitativa e qualitativa da produção científica. As pesquisadoras opinaram sobre essas perguntas de acordo com o que esperam, mesmo quando não tinham experiência no tema, como aquelas que ainda não são mães. A resposta das mulheres que ainda não são mães se justifica por nos permitir fazer uma estimativa da expectativa sobre a produção, em comparação com a realidade percebida daquelas que já são mães. As demais perguntas foram exclusivas para cada questionário e são relativas às expectativas, percepções e experiências de campo de cada mulher. Além das perguntas descritas acima, os questionários contam com outras questões que serão trabalhadas em estudos posteriores (anexo 2).

\section{RESULTADOS}

\subsection{Visão Geral}

Participaram da pesquisa 100 pesquisadoras que se identificam profissionalmente como etnobiólogas, sendo 22 da Argentina (A) e 78 do Brasil (B). Destas, 38 responderam o formulário "etnobiólogas que não são mães mas pretendem ser" (5 A e 32 B); 50 responderam o formulário sobre "etnobiólogas que foram mães após entrarem na carreira acadêmica" (10 A e 40 B); e por fim, 14 (7 A e 6 B) responderam as questões trazidas no formulários sobre "etnobiólogas que foram mães antes entrarem na carreira acadêmica". A diferença do número total de participantes entre os dois países aparentemente reflete o tamanho da população de etnobiólogas em cada país, visto os esforços realizados para atingir o máximo de mulheres. Apesar da diferença do número de participantes entre os dois países, as porcentagens das respostas foram muito parecidas entre as categorias em relação à maternidade, e, portanto, apresentamos os resultados sem discriminar valores percentuais 
para cada país (salvo os casos em que a porcentagem reflita mulheres de somente um dos países). Os resultados e gráficos para cada país estão discriminados no anexo 3.

A maioria (46) das participantes da pesquisa são professoras e/ou pesquisadoras associadas em instituição de ensino superior ou de pesquisa, seguidas por mulheres que estão atualmente no doutorado (21) (Figura 1). Também responderam mulheres que atualmente estão em estágio pós-doutoral ou trabalhando com a etnobiologia em cargos independentes, sem vínculo com nenhuma instituição (9 para os dois casos), no mestrado (5), além de mulheres que se consideram etnobiólogas, mas estão trabalhando em outro tema atualmente (4) e mulheres que estão sem trabalho remunerado (6) (Figura 1). Nessas três últimas categorias somente se enquadraram mulheres brasileiras.

\section{Estágio do percurso acadêmico}

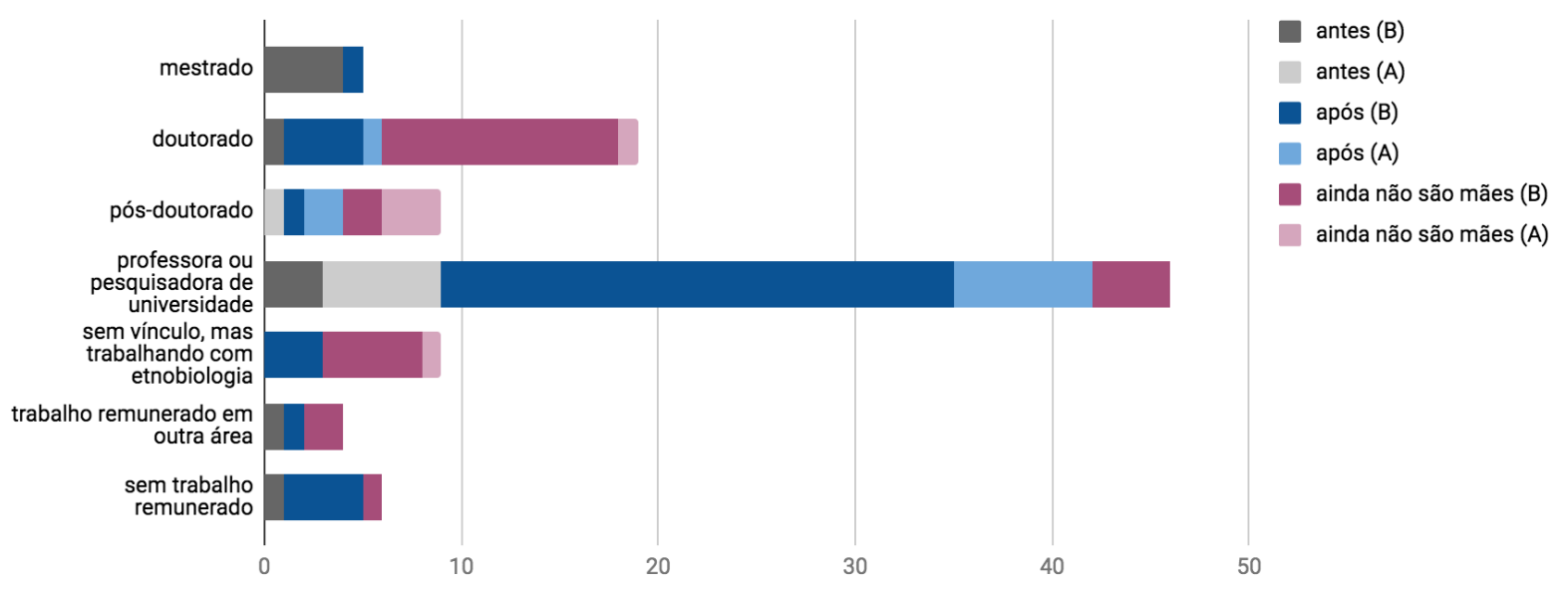

Figura 1: Estágio do percurso acadêmico das participantes da pesquisa de acordo com suas nacionalidades (Argentinas -A; Brasileiras- B) e com o questionário que responderam (etnobiólogas que foram mães antes de entrarem na carreira científica - antes; etnobiólogas que foram mães após entrarem na carreira científica após; etnobiólogas que não são mães mas pretendem ser - ainda não são mães). Fonte: as autoras (2020).

No tocante às questões acadêmicas e de produtividade, a maioria (77\%) acredita que a maternidade tem um impacto negativo na quantidade de produção científica (Figura 2). Por outro lado, 21\% acreditam que a maternidade não causa impacto nenhum na produtividade, considerando então que há uma estabilidade no quantitativo da produtividade acadêmica. Por fim, apenas 2\% das etnobiólogas acreditam que a maternidade pode resultar em um aumento quantitativo na produção acadêmica, correspondendo a duas mulheres do Brasil e nenhuma da Argentina. Em relação à qualidade da produção, 49\% das participantes acreditam que a maternidade não causa impacto qualitativo na produção científica (estabilidade) (Figura 3), e 42\% acreditam que a 
maternidade tem um impacto negativo na qualidade da produção científica, enquanto $8 \%$ acreditam que a maternidade pode ter impacto positivo.
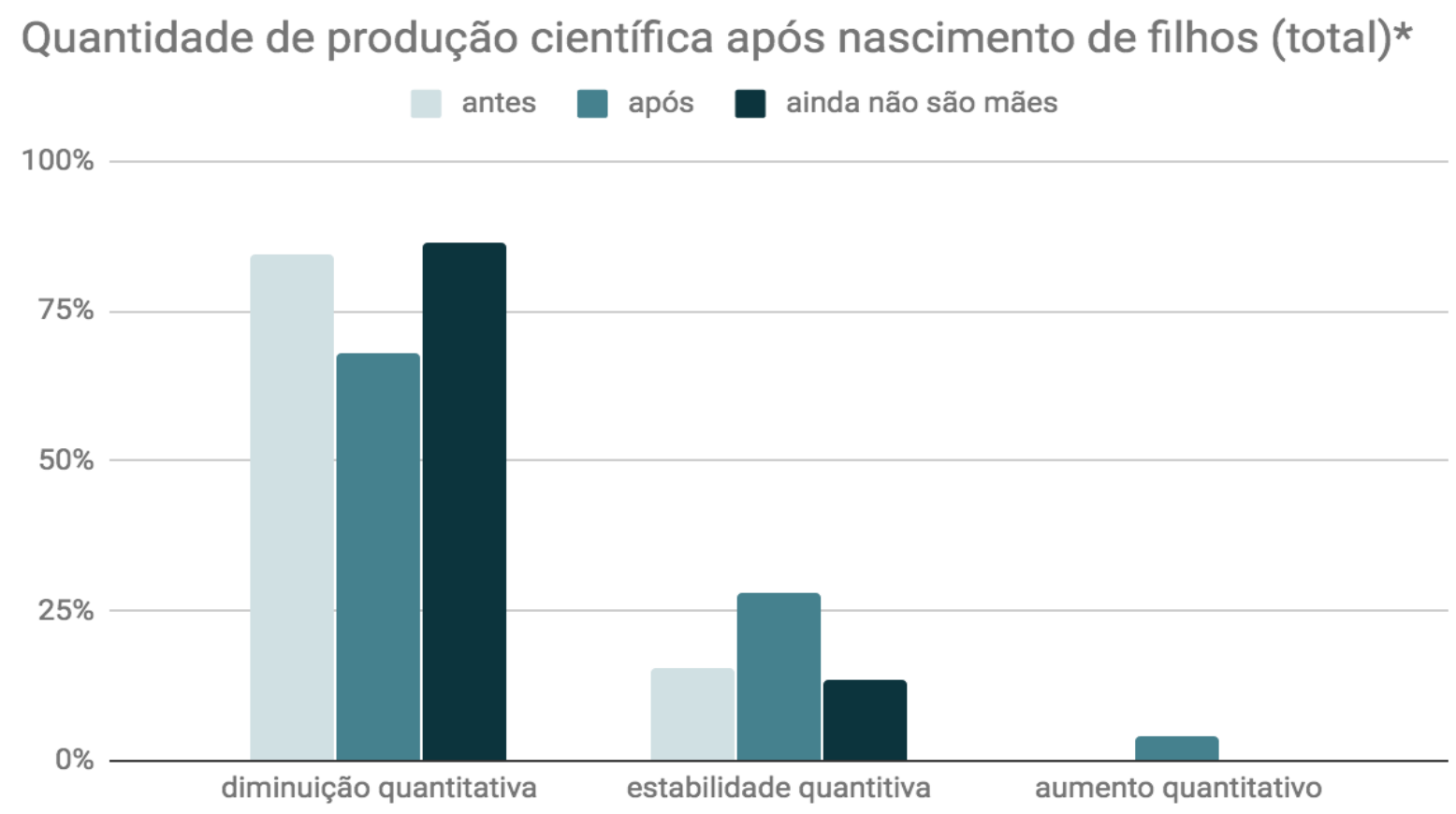

Figura 2: A quantidade de produção científica após o nascimento de um filho de acordo com a percepção das participantes separado por cada categoria em relação à maternidade (mulheres que foram mães antes de entrarem na carreira científica - antes; mulheres que foram mães após entrarem na carreira científica - após; mulheres que não são mães mas pretendem ser - ainda não são mães). Fonte: as autoras (2020).

*Aquelas que ainda não tiveram filhos, responderam com o que esperavam que aconteceria se tivessem filhos.

\section{Qualidade de produção científica após nascimento de filhos (total)* antes $\square$ após $\square$ ainda não são mães} $60 \%$

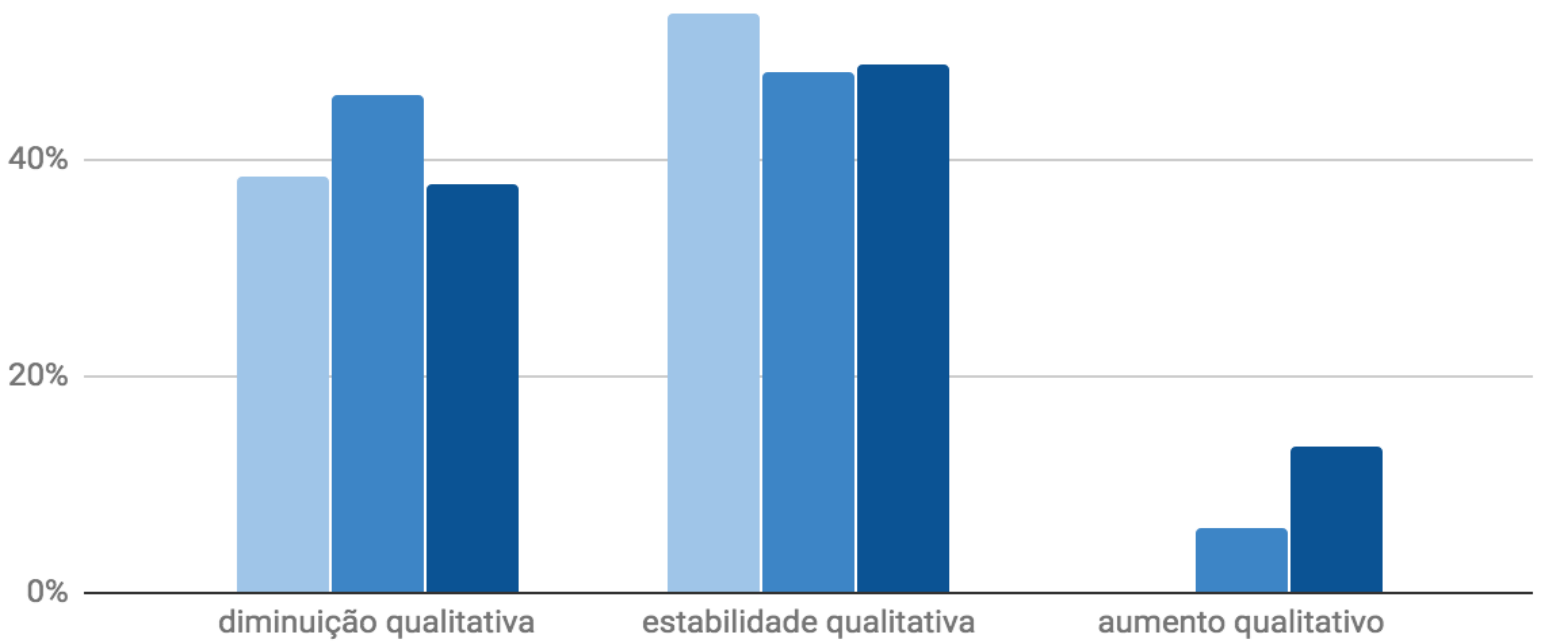


Figura 3: A qualidade da produção científica após o nascimento de um filho de acordo com a percepção das participantes separado por cada categoria em relação à maternidade (mulheres que foram mães antes de entrarem na carreira científica - antes; mulheres que foram mães após entrarem na carreira científica - após; mulheres que não são mães mas pretendem ser - ainda não são mães). Fonte: as autoras (2020).

*Aquelas que ainda não tiveram filhos, responderam com o que esperavam que aconteceria se tivessem filhos.

\subsection{Etnobiólogas que não são mães mas pretendem ser}

A média de idade entre as pesquisadoras acessadas em nosso trabalho foi de 30,8 anos, com mínima de 23 e máxima de 44. Entre essas, 89,4\% (sendo 100\% A e 78,8\% B) acreditam que adiaram o desejo de ter filhos por estarem desenvolvendo uma carreira acadêmica. Embora essa porcentagem tenha sido alta em ambos países, no Brasil apenas 9,4\% se arrependem de ainda não terem tido filhos. No entanto, na Argentina, uma grande proporção dessas mulheres $(66,7 \%)$ mostram arrependimento por ainda não terem filhos devido às obrigações com seus trabalhos acadêmicos. Em relação a perspectiva que as etnobiólogas que ainda não são mães têm sobre o momento mais adequado para vivenciar essa condição em suas vidas, 51,3\% pretendem ter filhos apenas quando estiverem em algum cargo de pesquisadora associada a instituição científica ou professora universitária; $16,2 \%$ pretendem ter filhos quando estejam realizando o doutorado; $8,2 \%$ quando estiverem no pós-doutorado e; $10,8 \%$ não estipula nenhum estágio do percurso acadêmico para ter filhos, e a mesma proporção pretende sair da vida acadêmica para ter filhos (Figura 4). Todas as participantes acreditam que a presença de filhos poderia causar mudanças em sua trajetória acadêmica.

\section{Estágio do percurso acadêmico em que pretendem ser mães} $60 \%$

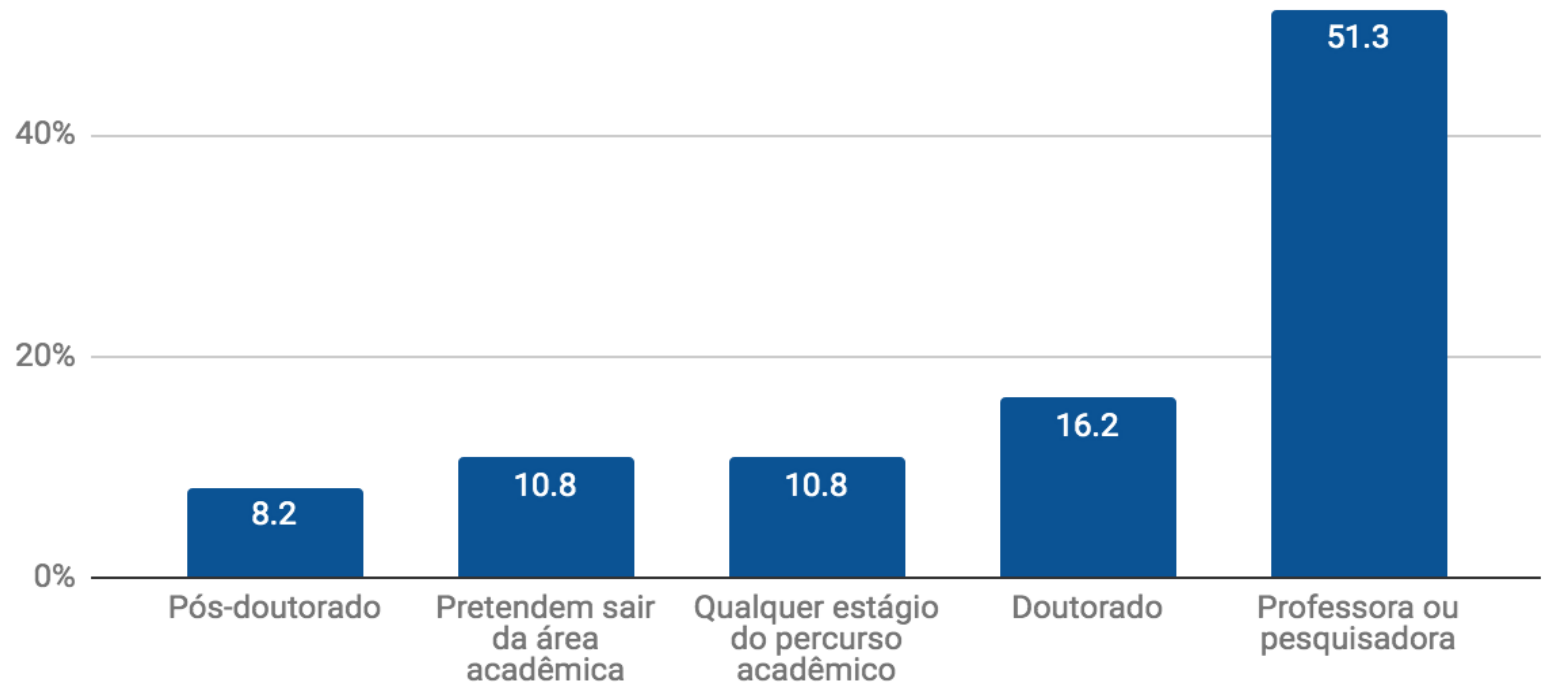


Figura 4: Porcentagem do estágio do percurso acadêmico em que etnobiólogas que ainda não são mães pretendem ter seu primeiro filho. Fonte: as autoras (2020).

Especificamente sobre mudanças na quantidade de produção científica, 86,5\% das etnobiólogas que ainda não são mães acreditam que a maternidade traria uma diminuição no número de produções científicas. Essa alta porcentagem representa $100 \%$ das participantes argentinas e $84,4 \%$ das brasileiras. Nenhuma das etnobiólogas que responderam o questionário acredita que haveria uma mudança positiva no número de produção científica, e apenas cinco (5) brasileiras $(13,5 \%$ do total) acreditam que não haveria mudança na quantidade de produção científica (Figura 2).

A maioria das etnobiólogas que ainda não são mães 48,7\%, acredita que a qualidade de produção científica não mudaria após o nascimento de um filho. Para 37,8\% dessas mulheres (todas brasileiras), haveria decréscimo qualitativo na produção científica e para $13,5 \%$, poderia haver aumento qualitativo (Figura 3).

\subsection{Etnobiólogas que foram mães antes entrarem na carreira acadêmica}

A média de idade entre as participantes que foram mães antes de ingressarem na carreira acadêmica foi de 48,7 anos, com mínimo de 35 e máximo de 59 anos. A média do número de filhos por pesquisadora é 1,85 (entre 1 e 3 ). A média de idade do primeiro filho dessas participantes foi de 21,15 anos, com idade mínima de 6 e máxima de 37. Aproximadamente metade $(53,8 \%)$ dessas mulheres acha que demorou a entrar na área acadêmica devido às ocupações com a maternidade, mas apenas 15,3\% (todas argentinas) se arrependem de não haver ingressado na carreira acadêmica antes, devido a ocupação com os filhos. Um percentual de 38\% tiveram outro filho após ingressar na carreira acadêmica e $23 \%$ gostaria de ter tido mais filhos, mas decidiu evitar devido às suas ocupações na área acadêmica. A maioria (77\%) está satisfeita com a quantidade de filhos que tem no momento.

Entre essas mulheres, $86 \%$ relatam que tiveram que deixar de fazer trabalho de campo alguma vez ou reduzir muito o tempo em campo em função das ocupações da maternidade. Todas já realizaram trabalho de campo sem os filhos, e 77\% das participantes já levaram seus filhos ao trabalho de campo por não ter com quem deixar o cuidado dos filhos (Figura 5).

Sobre a quantidade de produção científica, $84,6 \%$ das participantes acreditam que a maternidade tem impacto negativo no quantitativo de suas produções científicas. Nenhuma das etnobiólogas que responderam a esse questionário acredita que a maternidade tem 
impacto positivo no número de produção científica, e 15,4\% acreditam que a maternidade não causa impacto na quantidade de produção científica (Figura 2).

Sobre a qualidade de produção científica, 53,8\% acreditam que a maternidade não causa impacto nesse aspecto da produção científica e 38,4\% acreditam que a maternidade tem impacto negativo na qualidade de produções científicas. Nenhuma participante acredita que a maternidade tem impacto positivo na qualidade da produção científica e uma das participantes não respondeu a essa pergunta (Figura 3).

\subsection{Etnobiólogas que foram mães enquanto seguiam sua trajetória acadêmica}

A média de idade das participantes que se enquadram no perfil deste questionário é de 40,4 anos, com mínimo de 28 e máximo de 69 anos. A média do número de filhos por participante é 1,35 filhos (entre 1 e 3). A média de idade, em anos, do primeiro filho das participantes foi de 8,65 , com mínima de 0 e máxima de 40 . A maioria (80\%) está satisfeita com o número de filhos que tem até o momento, $20 \%$ se arrependem de não ter tido outros filhos ou de atrasar muito o momento de tê-los, devido às suas ocupações profissionais. Além disso, poucas participantes que responderam a esse questionário (12\%) se arrependem de terem sido mães durante a sua trajetória acadêmica, sendo todas brasileiras.

Entre essas pesquisadoras, $82 \%$ acreditam que tiveram que deixar de fazer trabalho de campo ou reduzir muito o tempo em campo em função das ocupações da maternidade. Mais da metade (55\%) já levaram seus filhos para o lugar onde realizam seu trabalho de campo e/ou já realizaram trabalho de campo longe dos filhos (66\%) (Figura 5). É importante ressaltar que muitas dessas mães têm filhos muito pequenos, e que provavelmente ainda não passaram pela necessidade de ter que ir a campo desde que seus filhos nasceram. Se incluímos apenas aquelas mães com filhos maiores de 3 anos, a porcentagem de pesquisadoras que realizaram trabalho de campo longe dos filhos, os valores percentuais aumentam para 92\%. Também aumenta para $80 \%$ a porcentagem de mulheres que levaram seus filhos a campo por não terem com quem deixá-los.

Entre essas mulheres, $68 \%$ percebem que a maternidade tem impacto negativo na quantidade de produções científicas, e $28 \%$ acreditam que a maternidade não causa impacto na quantidade de produção científica. Apenas duas brasileiras (4\%) relataram perceber que a maternidade causa crescimento no número de produção científica (Figura 2).

Sobre a qualidade de produção científica, a maioria das mulheres que responderam esse questionário (48\%) não percebem que a maternidade causa algum impacto na qualidade da produção científica, relatando estabilidade qualitativa. Para $46 \%$ a 
maternidade tem impacto negativo e para 6\% (3 brasileiras) a maternidade tem impacto positivo na qualidade da produção científica (Figura 3).

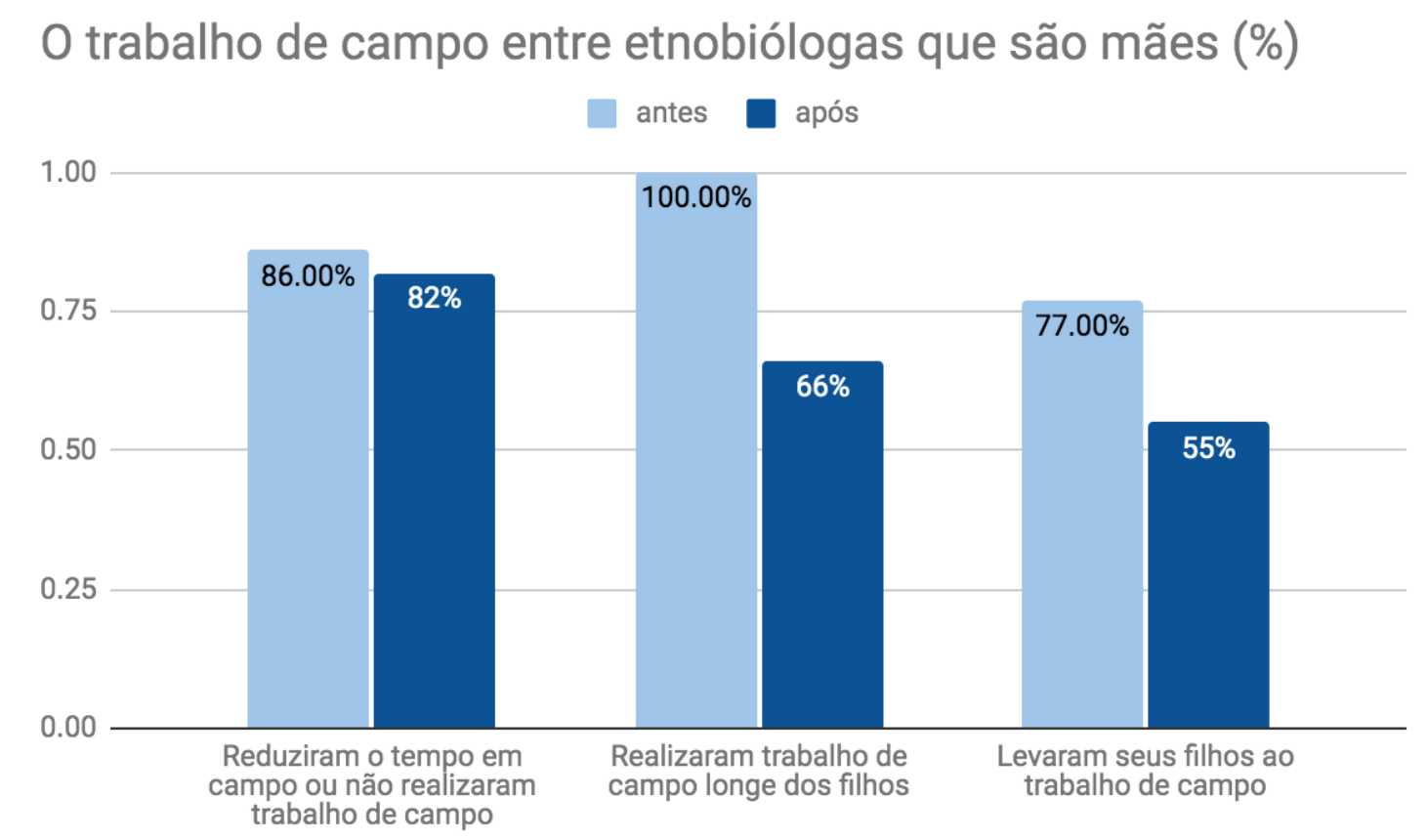

Figura 5: Porcentagem de mães etnobiólogas que tiveram que reduzir o tempo em campo ou deixar de realizar trabalho em campo ou reduzir o tempo estimado para esse trabalho, que tiveram que realizar trabalho de campo deixando os filhos sobre cuidados de outras pessoas e que tiveram que levar os filhos para campo por não terem com quem deixá-los, separado entre aquelas etnobiólogas que foram mães antes de entrar no percurso acadêmico (antes) e aquelas que foram mães após estarem na carreira acadêmica (após). Fonte: as autoras (2020).

\section{DISCUSSÃO}

Ao analisarmos o perfil das participantes, percebemos que a maioria das etnobiólogas que já são mães são professoras universitárias ou pesquisadoras associadas a alguma instituição de pesquisa. Poucas mães estão em outros estágios do percurso acadêmico, enquanto as etnobiólogas que não são mães estão, em sua maioria, no doutorado. Também percebemos que poucas mulheres foram mães antes de entrarem no percurso acadêmico, e a maioria destas correspondem a mulheres de maior idade, que foram mães em um contexto cultural diferente do atual, em que a pressão para uma mulher exercer a maternidade era maior (SCAVONE, 2001). Essa análise rápida no perfil das mulheres que responderam aos questionários mostra que, de acordo com a percepção das participantes, atualmente o melhor momento escolhido para ter um filho é no final do percurso acadêmico, quando há maior estabilidade da vida profissional, já que a média de idade dos 
filhos das cientistas que foram mães após estarem no percurso é baixa. Isso é reforçado pelas respostas das etnobiólogas que ainda não são mães à pergunta sobre quando seria o melhor momento de ter um filho, indicando, na maioria, a necessidade de terem um vínculo empregatício como professoras ou pesquisadoras.

Embora possa parecer óbvio que atualmente se busque essa estabilidade profissional como requisito para criar uma nova pessoa, tal estabilidade pode demorar muito para ocorrer numa carreira científica, o que resulta em adiar por um tempo longo demais o desejo de algumas mulheres em serem mães. Willians e Ceci (2012) já alertaram para o fato de que, na carreira científica, chegar a uma real estabilidade profissional desejada, que seria o papel de professora titular em uma universidade, é quase impossível para uma mulher antes de ter filhos. A maioria das profissionais que chegam a esse patamar, estão em uma idade em que a fertilidade do corpo está muito reduzida, impedindo-as ou dificultando-as de engravidar. As autoras construíram um gráfico que mostra que na verdade, o período entre 30 e 37 anos, é um período crucial tanto para a vida particular daquelas pessoas que desejam ser mães, como para a vida acadêmica. O que acontece é uma sobreposição dos períodos mais importantes da vida das cientistas, e o tempo dedicado a cada uma dessas duas atividades (criar um filho e fazer ciência), quando ocorrem juntas nota-se uma interferência na qual, frequentemente, a dedicação a uma dessas atividades prejudica a execução da outra.

Essa questão é especialmente importante em alguns países onde existe um limite de idade para ingressar como pesquisadora, como era o caso da Argentina até pouco tempo atrás. Até o ano de 2017, na Argentina, uma mulher só poderia concorrer em convocatórias para iniciar a carreira como pesquisadora em universidades públicas antes dos 35 anos, o que de certa forma implica que até essa idade ela teria que ter terminado o pós-doutorado com um currículo suficientemente competitivo. Esse poderia ser um grande desafio para aquelas mulheres que são mães. Talvez essa limitação maior das mulheres da Argentina em relação às mulheres do Brasil, onde nunca houve esse limite etário, seja responsável por uma perspectiva mais negativa das participantes em relação à conciliação maternidadecarreira científica, considerando que apenas pesquisadoras brasileiras responderam que pode haver mudanças positivas na produção científica após a maternidade, sejam qualitativas ou quantitativas. Além disso, uma proporção muito maior de argentinas que de brasileiras se arrependem de ainda não terem tido filhos, por fim, associamos também à isso, o fato de que apenas mulheres argentinas se arrependem de terem tido filhos antes de ingressarem na academia. No entanto, salientamos que, considerando esses resultados, 
qualquer diferença encontrada entre os dois países também pode ter ocorrido devido ao pequeno número de participantes da Argentina.

Independentemente da sua nacionalidade, a maioria massiva das participantes percebe um ônus na vida acadêmica ao conciliar a maternidade com sua carreira, principalmente no que tange ao quantitativo de produção científica, além de que uma grande porcentagem percebe também uma diminuição qualitativa. Considerando os caminhos que fazem a ascensão no mundo acadêmico, em que a quantidade de publicações tem um peso às vezes maior que a qualidade, esse efeito da maternidade na produção científica pode definir o sucesso de etnobiólogas em concursos públicos e editais de financiamento de pesquisa. Para Hal (2010), o aumento no número de mulheres cientistas nas últimas décadas, em vez de facilitar o caminho acadêmico para pesquisadoras, elevou os padrões que medem sua produtividade. O peso que a maternidade pode ter nessa competição por produtividade é tão forte que, algumas cientistas, inclusive afirmam que as mulheres que triunfam como cientistas, ou não têm filhos ou têm alguém realmente disposto a dividir as atividades familiares (HAL, 2010).

Em nossos resultados, é importante ressaltar que o ônus produtivo também é esperado por aquelas mulheres que ainda não são mães. Essas etnobiólogas esperam, em sua maioria, que haja uma diminuição no número de produção científica quando se tornarem mães. Na verdade, as respostas das mulheres que ainda não são mães parece refletir a realidade vivida por aquelas etnobiólogas que já são mães, já que as porcentagens são bem próximas entre as três categorias das entrevistadas. Essa comparação mostra que possivelmente essas mulheres ainda não foram mães porque sabem o quanto isso afetaria sua produção, prejudicando sua carreira científica. De fato, a maioria dessas mulheres afirmam terem adiado o desejo de ser mães por estarem na carreira científica. E, como já mencionamos, uma porcentagem grande de argentinas se arrepende por ainda não ter tido filhos, embora entre as brasileiras esse arrependimento atinja a minoria.

Nesse sentido, é importante também chamar a atenção para aquelas mulheres que pretendem sair da área acadêmica para realizar o desejo de ser mãe, possivelmente porque julgam impossível conciliar as duas atividades. Em uma perspectiva mais ampla, podemos esperar que algumas importantes pesquisas etnobiológicas podem ser abandonadas para que essas mulheres sigam seus planos pessoais, e que essas mulheres abandonarão uma carreira já iniciada por não visualizarem uma possível conciliação com a maternidade. A este respeito, um relatório estatístico elaborado a pedido do Observatório de Direitos Humanos da Universidade Nacional de Córdoba (AGOSTINI \& SCHIAVI, 2017) indica que a 
atribuição de papéis femininos relacionados ao cuidado (de crianças, de idosos, etc. ), ao trabalho doméstico e à área profissional constituem uma dupla jornada - ou tripla jornada, no caso das mulheres politicamente ativas - que de certa forma determina que mulheres não assumam alguns cargos profissionais ou desistam de alcançar determinados espaços que as mulheres não percebem como seus.

Apesar desse lamentável quadro, as etnobiólogas que pretendem sair da área acadêmica para serem mães somam a minoria, correspondendo à mesma proporção de mulheres que afirmam que poderiam ter um filho em qualquer estágio do percurso acadêmico. Para essas mulheres, a maternidade parece não apresentar um desafio potencialmente tão grande para seguir com sua carreira acadêmica. Nesse sentido, também temos que deixar claro que, apesar de representar uma proporção muito pequena de pesquisadoras, existe a perspectiva de que a maternidade leva ao aumento de quantidade e qualidade de produção científica. Essa perspectiva também é demonstrada por mulheres que já são mães e possivelmente podem comprovar esse aumento. Ward \& Wolf-Wendel (2004) comentam sobre o efeito positivo da maternidade sobre a produtividade, afirmando que estar envolvido em múltiplas funções pode ter efeitos favoráveis na autoestima e que mulheres que têm filhos também podem ter melhor "saúde, energia e resistência do que mulheres sem filhos", o que acarretaria em um melhor rendimento acadêmico. Nessa mesma linha Stack (2004) afirma que criar filhos pode motivar cientistas a trabalhar mais para oferecer a eles melhores condições de vida. Com base em nossos resultados, possivelmente essas explicações fazem sentido para a minoria das etnobiólogas.

Para além das publicações e na sua consequência para o sucesso acadêmico, a realização do trabalho científico em si também se torna desafiadora se coincide com a maternidade, especialmente na área da etnobiologia, em que o trabalho de campo é fundamental. Uma grande proporção de etnobiólogas que são mães afirmam que tiveram que deixar de fazer trabalho de campo ou reduzir muito o tempo em campo devido às ocupações com a maternidade, principalmente aquelas com filhos maiores de 3 anos, provavelmente porque até essa idade dos filhos ainda é possível trabalhar com dados coletados antes da maternidade. Após essa idade, essas mulheres têm que escolher entre conseguir alguém que realmente se responsabilize para cuidar dos filhos enquanto estão em campo (por isso também diminuem muito seu tempo de trabalho nessa atividade) ou levar os filhos ao trabalho.

A porcentagem de etnobiólogas que levaram seus filhos a campo é enorme entre aquelas com filhos maiores de 3 anos. Nessas situações se percebe claramente o que Hal 
(2010) chama de "two body problem", referindo-se à busca de equilíbrio entre as responsabilidades familiares e a carreira científica. Em campo, uma pesquisadora está em seu ambiente de trabalho enquanto lida com a tarefa de cuidar dos filhos, possivelmente porque não há opção alternativa ou porque a opção alternativa não é viável ou vantajosa. A maioria tem também, algumas vezes, a oportunidade de realizar trabalho de campo enquanto outra pessoa se ocupa dos cuidados dos filhos, já que quase todas relataram ter realizado atividades de campo nessas circunstâncias. Aparentemente, essas oportunidades são fortuitas, não se configurando como uma divisão do trabalho contínuo que é a lida com as crianças, mas sim como uma ajuda. Nesse sentido, salientamos que essa ajuda não ocorre sempre, uma vez que muitas mulheres que tiveram essa oportunidade, também já tiveram que levar seus filhos a campo.

Temos que lembrar que nem todo trabalho de campo é seguro com a companhia de uma criança. Apesar de não constar em nossos questionários, muito possivelmente algumas mulheres tiveram que mudar o foco de sua pesquisa, alterando seu trabalho de campo, para que fosse possível viagens mais curtas ou em lugares de maior segurança para eventualmente poder levar seus filhos.

Também não perguntamos sobre a opinião de outros colegas cientistas sobre como essas mães conciliam a maternidade com seu trabalho, mas o estudo de Silva et al. (2019) mostra que as mães etnobiólogas sofrem preconceito por seus pares. Outros trabalhos mostram que as mulheres omitem a maternidade aos seus colegas acadêmicos e tentam fazer ciência como "se não fossem mães" (HAL, 2010). Nossos resultados mostram que as etnobiólogas passam por inúmeras dificuldades ao se tornarem mães, e que isso pode afetar a realização de suas atividades acadêmicas de maneira significativa. Por mais que haja mães etnobiólogas que consigam um grande sucesso acadêmico, fica claro que não há equidade no percurso acadêmico entre mães e não mães, e que essa falta de equidade pode levar mulheres a adiarem seu desejo de serem mães ou atrasarem seu percurso acadêmico por serem mães. Essa diferença se soma à desigualdade entre etnobiólogos e etnobiólogas relatada por Silva et al. (2019), ainda mais se considerarmos que até mesmo a intenção em ser mãe afeta o caminho acadêmico de mulheres muito mais duramente que a intenção de ser pai afeta a vida científica de homens (WILLIAN \& CECI, 2012).

\section{CONCLUSÕES}

Sabemos que a ciência, como muitas áreas profissionais, foi historicamente construída por homens e para homens e que pouco foi feito para acomodar a entrada de 
mulheres na área acadêmica carrega essa história. A etnobiologia, apesar de ser particularmente uma ciência que valoriza a diversidade e estuda mudanças culturais de diferentes populações, não foge dessa regra, não tendo acumulado as mudanças que acompanham a grande diversidade de cientistas e suas singularidades. Em outras palavras, a evolução da etnobiologia ainda não considerou a pluralidade de mulheres e de outros grupos minoritários que participam da sua construção e precisa ser reestruturada para acomodar esses grupos, principalmente aqueles responsáveis pela criação de novas pessoas. Mulheres etnobiólogas não têm que se adaptar a uma maneira pré-existente de fazer etnobiologia, buscando atuar como se não tivessem filhos ou não os quisessem ter, apesar de que muitas o fazem com grande êxito.

Mudanças culturais são necessárias e inevitáveis, e elas ocorrem em grandes e pequenas escalas. Enquanto políticas públicas não são delineadas, de modo que reduzam a desigualdade entre aquelas pessoas com responsabilidades familiares e aquelas livres de tais responsabilidades - por exemplo, com maior tempo de licença maternidade, auxílio técnico em campo para mulheres que são mães, auxílio financeiro para conseguir cuidador especializado, diminuição das medidas de produtividade em concursos e editais para aquelas mulheres que são mães, etc - sugerimos que nós, etnobiólogas, etnobiólogos e cientistas de qualquer área (especialmente aqueles que ocupam cargos de avaliadores e orientadores), possamos olhar para o papel de mães cientistas de uma maneira diferente, livre de preconceitos e abertos a oferecer qualquer ajuda que possa ser necessária.

\section{AGRADECIMENTOS}

Ao grupo Parent in Science, pela inspiração. A todas as etnobiólogas que responderam aos questionários.

\section{REFERÊNCIAS BIBLIOGRÁFICAS}

AGOSTINI, A.; SCHIAVI, N. INFORME: La presencia de las mujeres en la Universidad y su participación política en órganos de gestión y representación. UNC, 2017. 76 pp.

ALBUQUERQUE, U. P. et al. Methods and techniques used to collect ethnobiological data. In: ALBUQUERQUE, U. P. et al. (Orgs.). Methods and Techniques in Ethnobiology and Ethnoecology. Humana Press, New York, 2014. p. 15-37.

BRUSCHINI, M. C. A. Trabalho doméstico: inatividade econômica ou trabalho nãoremunerado? Revista Brasileira de Estudos de População, Rio de Janeiro, v. 23, n. 2, p. 331-353, 2006. 
BRUSCHINI, M. C. A. Trabalho e gênero no Brasil nos últimos dez anos. Cadernos de Pesquisa, São Paulo, v. 37, n. 132, p. 537-572, 2007.

CECH, E. A.; BLAIR-LOY, M. The changing career trajectories of new parents in STEM. PNAS. v. 116, n.10, p. 4182-4187, 2019. https://doi.org/10.1073/pnas.1810862116

FIORIN, P. C.; OLIVEIRA, C. T.; DIAS, A. C. G. Percepções de mulheres sobre a relação entre trabalho e maternidade. Revista Brasileira de Orientação Profissional, Porto Alegre, v. 15, n. 1, p. 25-35, 2014.

GUIL BOZAL, A. Mujeres y ciencia: techos de cristal. Eccos Revista Cientifica. v. 10. n. 1, p. 213-332, 2008.

HAL, L. "The problem that won't go away": Femininity, motherhood and science. Women's Studies Journal. v. 24, n. 1, p. 14-30, 2010.

LUNNEMANN, P.; JENSEN, M. H.; JAUFFRED, L. Gender bias in Nobel Prizes. Palgrave Communications. v. 5, n. 46, p: 1-4, 2019.

MACHADO, L. S. et al. "Parent in science: The impact of parenthood on the scientific career in Brazil". Proceedings of the 2nd International Workshop on Gender Equality in Software Engineering, 2019, pp. 37-40. doi: 10.1109/GE.2019.00017.

MAIRESSE, J., PEZZONI, M. Does Gender Affect Scientific Productivity? A Critical Review of the Empirical Evidence and a Panel Data Econometric Analysis for French Physicists. Dans Revue Économique v. 66, n. 1, p. 65-113, 2015.

ORTIZ GÓMEZ, T. Feminismo, mujeres y ciencia. En: RODRÍGUEZ ALCÁZAR, F.; MEDINA DOMÉNECH, R.; SÁNCHEZ CAZORLA, J. Ciencia, tecnología y sociedad: contribuciones para una cultura de la paz. Universidad de Granada, España. págs. 185-202. 1997.

SCAVONE, L. Maternidade: transformações na família e nas relações de gênero. Interface-Comunicação, Saúde, Educação, v. 5, n. 8, p. 47-59, 2001.

SILVA, T. C. et al. The role of women in Brazilian ethnobiology: challenges and perspectives. Journal Ethnobiology Ethnomedicine, v. 15, n. 44, p. 1-11, 2019.

STACK, S. "Gender, children and research productivity". Research in Higher Education, v. 45, n. 8, 891-920, 2004.

WARD, K.; WOLF-WENDEL, L. "Academic motherhood: Managing complex roles in research universities". Review of Higher Education, v. 27, n.2, 233-257, 2004.

WILLIAMS, W. M.; CECI, S. J. When scientists choose motherhood: a single factor goes a long way in explaining the dearth of women in math-intensive fields. How can we address it? American Scientist, Carolina do Norte, v. 100, n. 2, p. 138, 2012. 